\title{
O Processo de Trabalho do Técnico em Saúde Bucal e suas Relações com a Equipe de Saúde Bucal na Região Metropolitana da Grande Vitória, Espírito Santo, Brasil' Dental Hygienist Technicians' Working Process and their Relationship with the Oral Health Team in the Metropolitan Region of Vitória, Espírito Santo, Brazil
}

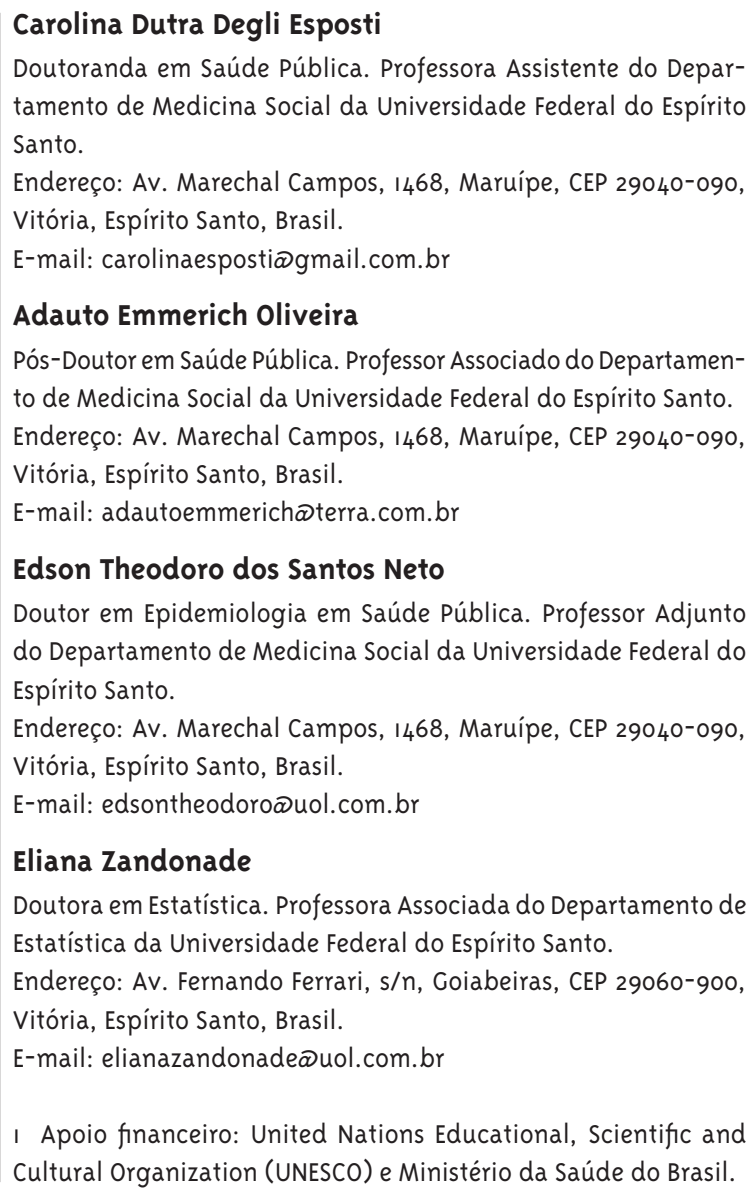

\section{Resumo}

O objetivo deste estudo é analisar a compreensão dos cirurgiões-dentistas (CDs) sobre o processo de trabalho e as relações da equipe de saúde com os Técnicos em Saúde Bucal (TSBs). Em cinco municípios da Região Metropolitana da Grande Vitória (RMGV), Espírito Santo (ES), Brasil, foram selecionados 18 sujeitos, a partir de uma amostra probabilística de 217 CDs que atuavam no Sistema Único de Saúde (SUS). Os sujeitos foram entrevistados a partir de um roteiro-guia semiestruturado, do qual constavam temas relacionados à organização do trabalho na saúde bucal; às atribuições e responsabilidades do TSB; à relação entre o cirurgião-dentista e o TSB; à relação com a equipe de saúde e autonomia do TSB. Os dados foram analisados a partir da Análise de Conteúdo sugerida por Bardin. Constatou-se que os CDs valorizam a importância da participação dos TSBs na reorganização do trabalho odontológico e a construção de uma relação de parceria e cooperação. Contudo, os CDs reconhecem que a relação com os TSBs é prejudicada pela desinformação sobre o processo de trabalho. Além disso, os CDs demonstram receios quanto à possibilidade de os TSBs tornaremse dentistas práticos e tomarem seu espaço no mercado de trabalho. Também há preocupações sobre a responsabilização legal dos CDs sobre atividades desenvolvidas pelos TSBs.

Palavras-chave: Formação de recursos humanos; Auxiliares de Odontologia; Educação profissional em saúde pública. 


\section{Abstract}

This study aims to assess dentists' understanding about the working process and the relationships of the health team with dental hygienist technicians (DHT). In five cities of the Metropolitan Region of Vitória, State of Espírito Santo, Southeastern Brazil, 18 subjects were selected from a probability sample of 217 dentists that worked in the National Health System. Subjects were interviewed by means of a semi-structured script, which contained topics related to work organization in oral health; roles and responsibilities of the DHT; relationship between the dentist and the DHT; DHT's relationship with health team and autonomy. The data were analyzed from the perspective of Bardin's Content Analysis. The data analysis indicates that dentists value the DHT's participation in the reorganization of dental work and the construction of a relationship of partnership and cooperation. However, dentists recognize that the relationship with the DHT is hampered by lack of information concerning the working process. In addition, dentists fear that the DHT become dental practitioners and take their place in the labor market. There are also concerns about legal liability of dentists concerning activities developed by DHT.

Keywords: Human Resources Education; Dental Auxiliaries; Dental Staff; Professional Education in Public Health.

\section{Introdução}

No processo de trabalho em saúde, existe um conjunto de autogovernos em operação dinâmica que o torna bastante complexo, havendo a necessidade de se considerar, nesse contexto, os jogos de interesses organizados como forças sociais que atuam na micropolítica do processo de trabalho (Faria e Araújo, 2010). Ao caracterizar o processo de trabalho em saúde, Nogueira (1999) reconhece a necessidade de considerar três aspectos fundamentais: o compartilhamento das características comuns a outros processos de trabalho, pois é um serviço que se baseia na inter-relação pessoal muito intensa; a integração dentre suas características de aspectos intelectuais e manuais e a fragmentariedade dos atos; e o reflexo nítido da divisão social e técnica do trabalho em saúde.

O taylorismo concebe a divisão técnica do trabalho em saúde em duas direções: uma vertical, na qual há um aumento das ocupações ou dos tipos de trabalhadores que participam de uma determinada hierarquia; outra horizontal, com aumento da diversidade de subunidades que participam do cuidado em saúde, imposta por uma ordem tecnológica e pela especialização. Isso provocaria o envolvimento dos trabalhadores em saúde, os quais assumiriam o compromisso com a qualidade na prestação dos serviços (Nogueira, 1999).

0 processo de trabalho em saúde visa promover e preservar as condições de saúde, à proteção e à prevenção contra fatores que a ameacem e assistência a indivíduos e grupos, no cuidado e na recuperação (Teixeira, 2003). Nesse sentido, um dos desafios da Educação Permanente em Saúde é o envolvimento integrativo entre profissionais e usuários e, nesse contexto, percebe-se a promoção da saúde como fortalecimento e capacitação dos diversos atores sociais para que atuem sobre os determinantes da saúde e superem os obstáculos à adoção das políticas públicas com ações intersetoriais (Frazão, 1998; Queluz, 2009). Assim, também o processo de trabalho na Odontologia norteia-se pelos princípios da promoção da saúde, superando o modelo biomédico, centrado na doença, por meio de um modelo de atenção integral à saúde bucal em que ocorra a incorporação progressiva de ações de promoção, 
proteção e recuperação da saúde e que vise à redução de fatores de risco (Brasil, 2004c).

No Brasil, a saúde bucal, historicamente, esteve à margem do sistema. Em 2000, o IBGE mostrou que 29,6 milhões de pessoas nunca haviam consultado um cirurgião-dentista (CD) (IBGE, 20oo). Além disso, o SB Brasil 2003, um estudo epidemiológico de base nacional, divulgado em 2004, revelou um CPO-D (número de dentes cariados, perdidos e obturados na dentição permanente) crescente e um aumento do percentual do componente perdido (P), ambos com o passar da idade (Brasil, 2004b), o que demonstrava, naquele momento, que a extração dental continuava a ser o principal tratamento oferecido aos males dentais e que a prevenção vinha sendo inexistente ou insuficiente. Esses resultados mostravam-se melhores que os observados nos levantamentos anteriores. Todavia, a despeito da melhora, a distribuição da cárie permaneceu desigual e sem mudança na proporção de dentes cariados não tratados, como analisado por Narvai e colaboradores (2006).

A inserção da atenção à saúde bucal na Estratégia Saúde da Família (ESF), a partir de 200o, buscou efetivar a promoção da saúde bucal no Brasil, muito discutida no âmbito teórico (Brasil, 2000, 2002), e enfatizada na Política Nacional de Saúde Bucal Brasil Sorridente. 0 objetivo era ampliar o acesso e melhorar as condições de saúde bucal da população (Brasil, 2004c), possibilitando a adequada atenção à saúde bucal aos diversos grupos populacionais nos diversos momentos do ciclo de vida. Assim, os incentivos para essa área cresceram, e as ações passaram a ser reorientadas. O SB Brasil 2010 revelou o avanço da política: maior acesso ao tratamento de qualidade, menos extrações dentárias e redução do CPOD em todas as faixas etárias (Brasil, 2010).

Como parte de um novo paradigma e com vistas à integralidade, foi instituído o trabalho em equipe na ESF também para a saúde bucal (Brasil, 2002, 2006). Essa inserção ampliou o campo de trabalho não só para os CDs, mas também para os níveis auxiliares pelo aumento do número de ESB (Brasil, 2008a). O Brasil possui 239.534 CDs registrados, número muito superior ao de Auxiliar de Consultório Dentário (ACD) (85.861 profissionais) e o de Técnico de Higiene Dental (THD) (12.385 profissionais) (CFO, s.d.), fato que pode decorrer tanto da falta de estímu- lo à formação adequada desses profissionais, quanto da recente regulamentação dessas duas profissões (Brasil, 2008b). A partir dessa legislação, houve definição clara de suas atribuições, direitos e deveres e mudança para as denominações de Técnico em Saúde Bucal (TSB), antigo THD, e Auxiliar em Saúde Bucal (ASB), antigo ACD, as quais serão utilizadas daqui por diante.

Essa legislação representa um impacto positivo para o processo de trabalho em saúde (Frazão e Narvai, 2011). No entanto, para resgatar essa dívida histórica social, pressupõe-se união de esforços dos diversos atores e, nesse contexto, a formação e a capacitação dos profissionais assumem caráter estratégico. Também são necessários novos enfoques para o trabalho em saúde bucal, em equipe, compartilhando conhecimento numa abordagem multidisciplinar e integral da assistência em saúde bucal (Costa, 2004). Para Sbravati e colaboradores (1999), a utilização de técnicos em Odontologia aumentaria a cobertura de programas odontológicos.

Pensando a formação desses profissionais, normalmente os docentes dos cursos de formação de TSB são CDs. No entanto, grande parte dos currículos de graduação em Odontologia baseava-se num modelo inadequado para atender as mudanças propostas pelo Sistema Único de Saúde (SUS). Tal como nas principais profissões de nível superior da área da saúde, os currículos dos cursos de graduação em Odontologia não contemplam conteúdos sobre Educação, uma visão mais ampla sobre o SUS e nem tampouco propiciam ao discente uma experiência prática efetiva com pessoal auxiliar, conforme discutido por Emmerich e Castiel (2009). Isso pode se refletir numa falta de capacitação adequada para exercer a função de docente para esses cursos técnicos.

Ainda nesse contexto, o grande número de profissionais de nível auxiliar com baixa escolaridade e sem curso de formação específico implica a necessidade de uma formação certificada e legalizada que contemple um saber qualificado que, para além da escolaridade, propicie "condições para o exercício da cidadania e a superação de desigualdades" (Pezzato e Cocco, 2004, p. 218). No Espírito Santo, a formação de TSBs constitui uma necessidade para viabilização do SUS, na medida em que os trabalhadores assumem as atribuições funcionais técnicas sem 
qualificação formal. Essa demanda foi explicitada no seminário "Ampliando a Oferta de Cursos do Centro de Formação em Saúde Coletiva (CEFOR)”2. Esse fato tornou-se notório com a integração das ESBs na ESF, que gerou aumento de demanda profissional, quantitativa e qualitativa.

Assim, o Núcleo de Educação e Formação em Saúde da Secretaria de Estado de Saúde do Espírito Santo (NUEFS) elaborou um plano de curso, autorizado pelo Conselho Estadual de Educação, que inicialmente contemplaria profissionais da Região Metropolitana da Grande Vitória (RMGV), sob a premissa de que os CDs inseridos no SUS desenvolveriam as atividades de ensino. No entanto, alguns desafios necessitavam ser superados para o desenvolvimento dessa proposta, tais como: indisponibilidade de material didático; compatibilização das diversas vinculações trabalhistas dos profissionais discentes e, sobretudo, a capacitação do $\mathrm{CD}$, profissional que seria o responsável pela maior parte dos conteúdos.

A partir dessa compreensão, é de se esperar que, além do domínio do conteúdo específico da Odontologia, o CD que se insira como docente nos cursos de formação para TSBs seja capaz de expressar suas competências de forma reflexiva e crítica, uma vez que, segundo Lobo Neto (2002) e Linãn (2009), além do domínio sobre o conteúdo da área de competência e a capacidade técnica pedagógica para o processo educacional de seus alunos na sociedade, o educador deve trabalhar instrumentos de reflexão, julgamento e decisão de ações.

Com base nas considerações, delineou-se o objetivo do presente estudo: analisar a compreensão dos CDs potenciais docentes para os cursos de formação de TSBs dos municípios da RMGV-ES sobre o processo de trabalho desses profissionais e sobre suas relações com os CDs e com a equipe de saúde.

\section{Metodologia}

A opção pela abordagem qualitativa deveu-se à necessidade de aprofundar o conhecimento acerca da compreensão que os CDs têm sobre o processo de trabalho do TSB e as relações que estes profissionais estabelecem com aqueles e com a equipe de saúde (Minayo, 2000).

A investigação foi desenvolvida na RMGV - ES, a qual é formada pelos municípios de Cariacica, Fundão, Guarapari, Serra, Viana, Vila Velha e Vitória e abriga quase metade da população total do Espírito Santo (46\%) e 57\% da população urbana do Estado. Juntos, produzem $58 \%$ da riqueza do Estado. Contudo, são municípios que apresentam entre si diferenças estruturais de desenvolvimento socioeconômico e populacional e também em relação ao acesso a serviços odontológicos (Brasil, s.d.).

Os sujeitos do estudo foram os CDs atuantes nos municípios da RMGV - ES, os quais participaram da primeira etapa da pesquisa que entrevistou 217 profissionais dos municípios de Vitória, Cariacica, Serra, Viana e Vila Velha (definidos pelo NUEFS como municípios que receberiam o curso técnico). Essa primeira etapa teve o objetivo de realizar a caracterização pessoal e de formação desses profissionais e seu interesse em lecionar no curso para TSB (Espírito Santo, 2008). Assim, foram definidos os seguintes critérios de inclusão que permitiriam a aproximação aos sujeitos que, numa análise preliminar e superficial, estariam mais preparados para atuar como docentes no curso para os TSB disponível na RMGV - ES: 1) declarar interesse em compor o grupo de docentes do curso de TSB; 2) possuir experiência de trabalho junto ao TSB; 3) possuir experiência na docência em sala de aula ou em campo de estágio de aulas práticas; 4) possuir pós-graduação (especialização, no mínimo); 5) ter participado de cursos oferecidos pelos serviços; 6) representatividade dos cinco municípios. Em relação aos critérios dois e três, foi considerado o maior tempo relatado pelos participantes. Garantindo a representatividade dos cinco municípios, foram selecionados assim 18 sujeitos para participarem dessa pesquisa, distribuídos segundo o município, a saber: três CDs de Cariacica, cinco de Serra, um de Viana, três de Vila Velha e seis de Vitória.

\footnotetext{
2 Em 2002, o seminário promovido pelo CEFOR (denominação do Núcleo de Educação e Formação em Saúde, anterior à Lei Complementar $n^{0}$ 317, publicada no DIO/ES em 3 de janeiro de 2005) reuniu aproximadamente 130 pessoas, entre profissionais da rede pública e secretários municipais de saúde do Espírito Santo. Teve como objetivo principal levantar necessidades de formação de nível técnico na área da saúde dos municípios do Estado.
} 
Para a coleta dos dados utilizaram-se entrevistas semiestruturadas, uma vez que, segundo Gaskell (2002, p. 65), esse recurso fornece informações para o desenvolvimento e a compreensão das relações entre os atores sociais e seu contexto de vida. São utilizadas para a "[...] compreensão detalhada das crenças, atitudes, valores e motivações, em relação aos comportamentos das pessoas em contextos sociais específicos".

Foi realizado um pré-teste do instrumento no mês de julho de 2008, com três sujeitos do Município de Vitória, através do qual puderam ser percebidas dificuldades na aplicação do roteiro-guia e falta de clareza em algumas questões-chave. Esse fato é esperado, pois, segundo Souza e colaboradores (2005), o pré-teste de roteiros de entrevistas com informantes previstos no desenho do projeto acaba levando a uma alteração da lista de temas e da forma de abordagem dos assuntos. Devido à necessidade de alterar algumas questões do roteiro-guia, essas três entrevistas não foram utilizadas na análise final.

Assim, as entrevistas foram realizadas, gravadas e posteriormente transcritas por um entrevistador treinado, no período de julho a setembro de 2008. A confidencialidade foi garantida pelo sigilo sobre o nome dos entrevistados, que foram identificados sequencialmente através de números arábicos, em sucessão à letra E (de entrevistado). Os nomes citados pelos sujeitos foram registrados apenas pelas iniciais. Essas duas codificações seguem as indicações de R. Gomes e colaboradores (2005) e Araújo (2001). 0 entrevistador também foi responsável pela correção das transcrições e pela análise do material, o que facilitou o processo de análise. Para Demo (1991), uma forma que se adapta à pesquisa qualitativa é a transcrição vivencial de um conteúdo participativo, dado pelo depoimento.

As entrevistas foram analisadas segundo a análise de conteúdo proposta por Bardin (2009), que busca compreender o sentido e o significado das falas dos sujeitos. Após exploração e leitura exaustiva do material, foram extraídas as seguintes categorias de análise: organização do trabalho na saúde bucal; atribuições e responsabilidades do TSB; relação entre o CD e o TSB; e relação com a equipe de saúde e autonomia do TSB.

O projeto de pesquisa foi aprovado pelo Comitê de Ética e Pesquisa da Associação Brasileira de Odontologia - Seção Espírito Santo, sob o protocolo 43/o6. Além disso, foram solicitadas às Secretarias Municipais de Saúde autorizações formais para execução da pesquisa e todos os sujeitos assinaram o Termo de Consentimento Livre e Esclarecido.

\section{Resultados e Discussão}

Partindo das entrevistas individuais, transcritas e corrigidas, estabeleceu-se a ligação entre as categorias extraídas para a análise, o depoimento do conteúdo vivencial dos sujeitos da pesquisa e a literatura produzida na área.

\section{Organização do trabalho na saúde bucal}

O trabalho em saúde bucal vem se desenvolvendo, ao longo da história, não só pela atuação dos CDs, mas também pelo trabalho desenvolvido pelos ASBs e TSBs, dentre outras categorias auxiliares (Liñan e Bruno, 2007; Narvai, 2003; Queluz, 2003). Ainda segundo esses autores, a falta da regulamentação dessas profissões e a discordância entre as diversas legislações, problema resolvido no final de 2008 (Brasil, 2008b), poderiam ser um fator complicador para o estabelecimento de uma organização do trabalho em saúde bucal capaz de atender às propostas de ampliação da atenção para além das ações curativas.

Na prática dos serviços estudados, os CDs necessitam entender a importância da participação de pessoal auxiliar, principalmente dos TSBs, na divisão das atividades e na organização do trabalho odontológico. A centralidade exercida historicamente pelo $\mathrm{CD}$, com monopolização do conhecimento científico, deve dar lugar ao compartilhamento e à colaboração e, para isso, os processos de trabalho construídos até então devem passar por modificações profundas (Esposti, 2007; Queluz, 2009). Também se deve ter em mente que conceitos como promoção de saúde e prevenção às doenças são chaves na construção de serviços que atendam às mudanças propostas para o sistema.

Durante a pesquisa, percebeu-se que os CDs identificavam tal necessidade na evolução da organização dos serviços em direção à atenção às necessidades da população. Para eles, é muito importante que os usuários tenham acesso à prevenção e à promoção 
de saúde bucal, que, na opinião deles, seriam de competência principalmente dos TSBs, sob supervisão dos CDs. Ainda nesse aspecto, consideram que esse contato deve ser anterior às ações de reabilitação dos danos, tradicionalmente única oferta de atenção em saúde bucal no Brasil. 0 depoimento a seguir ilustra esse entendimento:

[...] se ele tem um serviço organizado, em que o paciente tem acesso ao TSB antes de ir pro dentista, eu acho que o papel dele é importantíssimo aí. Tanto na orientação - né- todas, a alimentação, escovação e a própria profilaxia, eu acho que é uma prevenção de saúde, fazendo parte da equipe do PSF- né-ajudando o dentista na visita domiciliar [...]. (Eo6)

Além da atuação nas questões preventivas e de promoção de saúde, disseminando conhecimento e aumentando a qualidade do serviço, a organização do trabalho com a participação desse profissional ganha também com o aumento de produtividade e com a redução dos custos (Silva e col., 20o6; Serra e Sasso Garcia, 2002; Pezzato e Cocco, 2004; Kovaleski e col., 2005; Pereira e Moreira, 1992; Queluz, 2005). Sua função é realizar o maior número de tarefas possíveis para que o CD fique livre para os trabalhos mais exclusivos e específicos de sua competência (Queluz, 2003; Kovaleski e col., 2005), tais como o planejamento das ações e o tratamento mais complexo dos pacientes. Assim também entendem os CDs, conforme relatos abaixo:

[...] é importante você poder usar um técnico pra disseminação desse conhecimento, que na verdade fica preso ao cirurgião-dentista ou outras vezes ao técnico [...]. (Е18)

[...] às vezes fica muito sobrecarregado pro cirurgião-dentista fazer, ehhhhh, todas as funções que de repente pode delegar um TSB que seja bem capacitado - né. (Eo5)

Para que os TSBs possam exercer suas funções, há a necessidade de supervisão do CD responsável (Brasil, 2008b). Na verdade, os CDs percebem essa supervisão muito relacionada à prática clínica dos TSBs. O fato de estes terem um conhecimento técnico e científico mais restrito da área odontológica e trabalharem sob sua responsabilidade pode gerar um receio sobre os produtos advindos de sua prática e sobre o aspecto legal dessa responsabilização
(Narvai e col., 1989; Narvai, 2003). Segundo Serra e Sasso Garcia (2002), a delegação de funções pressupõe responsabilização. Essa preocupação com a supervisão sobre as atividades clínicas aparece, por exemplo, no seguinte depoimento:

[...] nestes trabalhos realizados na cadeira odontológica, tem que ter sempre um dentista supervisionando o trabalho dele... - né? (Eo7)

A organização do trabalho em saúde bucal deve contemplar a participação dos TSB, para que também realize atendimento clínico em ações individuais, havendo, assim, a necessidade de espaço físico adequado à sua atuação. Segundo a Portaria GM/MS n0648/2006 (Brasil, 2006), para garantir a atuação adequada dos TSBs, a modalidade II da ESB recebe incentivos para a aquisição de um consultório odontológico adicional (Pucca Jr., 20o6; Brasil, s.d.). A preocupação quanto à necessidade de espaço físico para atuação clínica adequada dos técnicos está expressa nos relatos:

[...] tem que fazer um link mesmo - né - do dentista com a população, tem que... poder trabalhar na cadeira também [...], mas aí tem que ter uma cadeira específica pra ele né [...]. (Eo4)

[...] Eu fico imaginando um trabalho com a TSB: duas cadeiras, eu numa, TSB em outra. Eu acho que ia ser um adianto danado, eu ia gostar [...]. (E01)

No entanto, para tornar isso realmente realidade, os gestores necessitam reconhecer a importância desse profissional, buscando vencer as barreiras que se colocam no caminho. Na década de 1980, inúmeras foram as discussões contra a atuação dos TSB (Narvai e col., 1989), e muitos avanços já ocorreram. A legislação que busca reorientar as práticas na atenção básica no Brasil é reflexo disso. A disponibilização, pelos serviços de saúde, de espaços físicos busca assegurar que esses profissionais possam ser aproveitados em suas atribuições e que contribuam, de fato, para a melhoria dos serviços, com a redução dos altos índices epidemiológicos das principais doenças de saúde bucal, como a cárie e a doença periodontal.

Nesse estudo, observou-se que os CDs percebem a importância do TSB na reorganização do trabalho em saúde bucal, tanto nas ações educativas e de promoção de saúde bucal quanto no consultório 
odontológico, em ações coletivas e também ações individuais.

\section{Atribuições e responsabilidades do Técnico em Saúde Bucal}

Aos TSBs pertencem as atribuições dos ASBs e também outras específicas (CFO, 2005; Brasil, 2008b). Contudo, para que os CDs possam supervisionar e delegar as funções aos TSBs, eles precisam estar cientes dessas atribuições. Quanto a esse aspecto, pelos relatos, a maioria dos sujeitos entrevistados parece conhecê-las. Além disso, num contexto de mudança do modelo de atuação no trabalho odontológico, com superação da lógica flexneriana, a atuação do TSB tem incorporado de forma acentuada as ações de promoção da saúde bucal, principalmente em escolas e outros espaços sociais (Frazão; Castellanos, 1999; Frazão, 1998). Os CDs têm percebido a importante atuação desses profissionais nas questões da promoção de saúde, como exemplifica essa fala:

[...] ele pode trabalhar nessa promoção de saúde através de palestras, revelação de placa, ehhh, escovação dental supervisionada, aplicação tópica de flúor, bochecho fluorado, respeitando as normas ditadas pelo CRO, pelo conselho - né - com supervisão [...]. (Е13)

Percebe-se, no entanto, que as ações estão limitadas quando se fala nos procedimentos clínicos, assim como discutido por Frazão e Castellanos (1999), Serra e Sasso Garcia (2002) e Queluz (2005, 2009). Caso os TSBs fossem mais bem aproveitados em suas atribuições clínicas, contribuiriam para diminuir a enorme demanda que ainda hoje vemos em muitas regiões. Para entender como é a divisão do trabalho entre CD e TSB, é importante conhecer a percepção que os CDs têm das relações que estabelecem junto aos TSBs.

\section{Relação entre o Cirurgião-dentista e o Técnico em Saúde Bucal}

A profissão de TSB somente recentemente foi regulamentada pela União (Brasil, 20o8b). Muitos CDs, durante sua formação, não têm qualquer tipo de experiência ou contato com os profissionais auxiliares e, muitas vezes, também não recebem informações adequadas sobre eles e nem são estimulados a conhecê-los. Além disso, muitos CDs nunca trabalharam em conjunto com TSBs (Cavaca e col., 2010). Embora haja estímulo para a incorporação desses profissionais nas ESBs (Brasil, 2006; Pucca Jr., 2006), a realidade é que essas relações ainda são incipientes. Assim, é importante conhecer como aqueles que já trabalharam ou trabalham com os TSB veem essa relação descrita pelos entrevistados:

[...] dentro das atribuições deles, o que eles fazem já é uma mão na roda, outra no volante. [...] a gente começa a trabalhar com uma pessoa assim, que tem uma capacitação e é incrivel a capacidade deles e como que você fica em sintonia [...]. (E18)

[...] pelo menos com a TSB que eu trabalho, a melhor possível, são colaboradores, é uma equipe. (Eo6)

Os sujeitos dessa pesquisa percebiam que a atuação dos TSBs tem a contribuir no trabalho em saúde bucal, principalmente numa relação de parceria e cooperação. Segundo Chaves (1986) e Queluz (2003, 2005), as profissões auxiliares surgem à medida que o conhecimento se acumula e seriam criadas, inicialmente, para executar operações de rotina, treinados pelos próprios CDs. Porém, os entrevistados narram que muitos colegas de profissão ainda não veem com bons olhos a atuação dos TSBs. Para alguns, é como se os TSBs competissem com eles no mercado de trabalho e, por esse motivo, muitas vezes, colocamse contra essa categoria (Brasil, 2005; Narvai e col., 1989; Narvai, 2003; Queluz, 2003; Queluz, 2005; Liñan e Bruno, 2007).

A situação econômica de nosso país e o grande número de CD provocam concorrência cada vez maior entre aqueles que buscam um espaço no mercado de trabalho. Para eles, o fato de existir outra categoria profissional que pode realizar parte de suas atribuições representa uma situação preocupante, assim como discutido por Narvai e colaboradores (1989), Narvai (2003), Queluz (2003, 2005) e Liñan e Bruno (2007). Os relatos que seguem deixam isso claro.

[...] tinha uns profissionais que eram contra, falavam que iam tomar a profissão e não sei o que, mas isso não é... besteira, no meu ponto de vista isso não existe não [...]. (Eo4)

[...] a TSB é... 'pra' certos profissionais ela num, ela, é como se estivesse invadindo o espaço deles - certo? [...]. (Ео3) 
Segundo Narvai e colaboradores (1989), o campo da Odontologia é amplo e seu mercado de trabalho é diverso. Com o intuito de captar a pequena parcela da população que dispõe de recursos financeiros para acessar aos serviços particulares, os CDs buscam reduzir custos e, numa visão reducionista, podem relutar em incorporar os TSBs. Dessa forma, o setor público é pressionado a absorver essa força de trabalho não ocupada. Nesse contexto, os CDs têm, não raramente, se colocado contra a divisão técnica do trabalho odontológico. Só que essa atuação isolada dos CDs dificulta a expansão do mercado de trabalho. Essa tentativa de reserva de mercado (Queluz, 2003) acaba por restringir a inclusão dos TSBs.

Além disso, outros fatores distorcem a visão dos CDs em relação aos TSBs. Há o receio de os TSBs se tornarem 'dentistas práticos' a partir do conhecimento adquirido para o desempenho da profissão (Narvai e col., 1989; Narvai, 2003). Isso acontece pelo fato de ambos trabalharem num campo comum de atuação, em núcleos bem próximos ${ }^{3}$. É verdade que a construção da cientificidade odontológica se deu com luta contra os práticos e ilegais (Queluz, 2003; Narvai e col., 1989; Brasil, 1994; Emmerich, 2000). No entanto, deve-se enfatizar que o TSB possui atribuições definidas, sendo dele exigido diploma ou certificado de curso reconhecido pelo MEC e registro pelo CRO. Portanto, esse profissional não pode ser confundido com o 'dentista prático'. Muitos são os CDs que se sentem ameaçados pelos TSBs, como exemplificam as seguintes falas:

[...] eu via pessoas com restrições, inclusive dentistas com medo do TSB virar um dentista prático. Já ouvi isso [...]. (E18)

[...] TSB querer invadir o espaço do dentista, dentista não aceita. Querer ir além - né? - do que seria a capacidade dela. Eu não sei, eu ouço [...]. (Еo1)

Por isso, entende-se como necessário um trabalho prévio de educação junto aos CDs, no sentido de esclarecê-los quanto às atribuições dos TSB, estimulando-os a desenvolver essa parceria. 0 mes- mo foi sugerido por um dos entrevistados:

[...] tem que informar, fazer o trabalho prévio de informação, inclusive com o dentista, porque o dentista éfechado pra receber. Ele acha que o profissional TSB vai tirar a vaga dele, ele acha que o TSB vai virar dentista prático - entendeu? [...] (Eog)

A formação dos CDs deveria envolver a relação com as categorias auxiliares, principalmente com os TSBs, como assinalado por Liñan e Bruno (2007), Serra e Sasso Garcia (2002) e Queluz (2003) e relatado como experiência proveitosa por Alcântara e Takahashi (2006). Na visão de alguns CDs, se o contato entre eles fosse precoce, a relação no serviço seria muito mais fácil. Não sendo uma relação muito frequente, fica difícil estabelecer uma harmonia em curto prazo. Os CDs, comumente formados numa visão de que ocupariam uma relação dominante na profissão e de que teriam o controle sobre a boca (Emmerich, 2000; Queluz, 2003), precisam, a partir da popularização da atuação dos TSBs, estabelecer uma nova posição, menos baseada em hierarquia e dominância e mais em cooperação e comunicação, para garantir que a participação dos TSBs na saúde bucal alcance seu objetivo.

O sujeito do trabalho em saúde bucal é coletivo. Assim, o trabalho do TSB se realiza plenamente, no seu sentido social, ao integrar-se a uma equipe de saúde bucal. Nesse sentido, somente a comunicação horizontal na experiência de trabalho entre esses profissionais pode desmistificar a visão de que os TSBs existem para tomar espaço dos CDs. Sendo pouca a experiência que os CDs têm no trabalho em conjunto com os TSBs e partindo da visão preconceituosa que muitos ainda têm dessa relação como sendo uma invasão de espaço, não é estranho que os CDs tenham restrições em atribuir responsabilidades aos TSBs no cotidiano dos serviços. Por isso, a importância em também se conhecer como vem se dando a relação entre TSB e os demais profissionais da saúde e, ainda, o grau de autonomia que ele dispõe numa equipe de saúde.

3 Núcleo aqui entendido como "[...] o conjunto de saberes e de responsabilidades específicos a cada profissão ou especialidade”, segundo Campos (CAMPOS, G. W. S. Subjetividade e administração de pessoal: considerações sobre modos de gerenciar o trabalho em equipes de saúde. In: MERHY, E. E.; ONOCKO, R. (Org.). Agir em saúde: um desafio para o público. 2. ed. São Paulo: Hucitec, 2002. p. 229-66.). Conforme esse mesmo autor, o campo de atuação corresponde aos "saberes e responsabilidades comuns ou confluentes a várias profissões ou especialidades [...]". 
Relação com a equipe de saúde e autonomia do Técnico em Saúde Bucal

Nos serviços de saúde tem-se trabalhado com o conceito ampliado de saúde, a partir do qual sua atenção requer também a atuação dos diversos profissionais na promoção e prevenção da saúde e no estabelecimento de ações intersetoriais. Assim, no que diz respeito à saúde bucal, há a ampliação e o estímulo à participação dos TSBs e dos ASBs (Frazão, 1998; Frazão; Castellanos, 1999). Em se tratando da ESF, os TSBs devem relacionar-se também com os demais integrantes das equipes de saúde da família (Brasil, 2006). Como o trabalho em equipe pode não ocorrer tão facilmente com os CDs, como discutido, fica a dúvida se o mesmo acontece em relação aos demais profissionais da equipe de saúde. Segundo os relatos, é assim que ocorre na prática:

[...] no Programa de Saúde da Família tem que ter uma interação de todos - né? Mas cada um, assim, na sua área [...]. (E15)

[...] aqui nesta unidade que eu trabalho, apesar dela não ser PSF, há uma interação grande com os outros profissionais. A gente se interage bem [...] Eu acho que acesso é tudo - 'tá? Se são pessoas muito fechadas, é difícil interagir em qualquer lugar [...]. (Eo6)

O trabalho em saúde pressupõe a necessidade de diálogo, já que suas ações acontecem pela relação entre sujeitos. Há grande dificuldade de se trabalhar em equipe no âmbito da saúde (Esposti, 2007; Peduzzi, 2001, 2007; Araújo e Rocha, 2007; R. S. Gomes e col., 2005). Ainda que se deva valorizar a polifonia, os profissionais devem trabalhar de forma uníssona, harmônica, valorizando o consenso e a comunicação entre seus integrantes. Nesse contexto, a desinformação sobre a profissão de TSB funciona como complicador para o estabelecimento do trabalho em equipe. Entretanto, com o aumento da abrangência da ESF e da divulgação de suas diretrizes, passou-se a se buscar um conhecimento mais aprofundado das diversas maneiras de se promover saúde e também da necessidade de se unir forças entre os diversos profissionais da saúde. Daí que as informações sobre os TSBs têm sido mais difundidas, mas talvez não o suficiente.

A interação entre os TSBs e os demais profis- sionais das equipes de saúde traz implicações na capacitação dos profissionais da saúde sobre a saúde bucal e também na promoção de saúde. Essa relação, para ser produtiva, deve ser pautada em confiança e na comunicação entre sujeitos com objetivos de trabalho comuns (Esposti, 2007). Para alguns, no entanto, a qualidade da relação e os frutos advindos dela dependem de como os TSBs lidam com a estrutura do serviço, como se colocam nele e se comprometem com suas atribuições. Um profissional consciente de suas atribuições e que recebe apoio institucional para desenvolvê-las tende a ser mais bem-aceito pelos demais profissionais. Os seguintes depoimentos ilustram essa afirmativa:

[...] eu acho que o TSB [...] fazendo o trabalho dele benfeito ele vai ser reconhecido pelos outros profissionais, tanto pelo cirurgião-dentista como pelos outros profissionais [...]. (Eo5)

[...] às vezes a equipe não facilita, vamos dizer assim, um pouco, não aceita bem. Mas assim, se ele se impor, se ele mostrar assim pra que que veio $e$ mostrar a função dele, não tem problema [...]. (E12)

O fato de não haver ainda um espaço ampliado no mercado de trabalho para os TSBs faz com que essa profissão seja pouco conhecida pela população em geral e, também, pelos outros trabalhadores da área da saúde. Os relatos a seguir apontam essas questões:

[...] muita gente não sabe o que é uma técnica de higiene dental e isso aí é uma profissão antiga [...]. (Еоз)

[...] os outros profissionais de saúde eles não têm um entendimento ainda do que érealmente uma TS, uma ('TSB') [...]. (Е10)

Esse desconhecimento por parte dos outros profissionais da saúde pode gerar desconfiança, a não delegação de funções e a não valorização do trabalho que ele desenvolve. Nem todos os profissionais conhecem as potencialidades do trabalho dos TSBs. Nesta pesquisa, alguns depoimentos demonstram que certos profissionais entendem que ele deve ser excluído de algumas atividades. No entanto, a reorganização do trabalho em saúde na atenção básica pressupõe o trabalho em equipe (Brasil, 2006), o qual está intimamente ligado à integralidade (Esposti, 
2007). Ao existirem profissionais que ao invés de buscarem compartilhar as atividades em prol da melhora da qualidade das ações criam barreiras a essa efetivação, o sucesso das políticas públicas pode estar comprometido.

Outra questão é que, após a formação técnica, os TSBs, possivelmente antes ASBs, passam a executar um rol maior de atividades e podem até atuar como supervisores do trabalho dos ASBs. Essa relação, muitas vezes, não é bem aceita por aqueles que antes dividiam as funções e que agora podem passar a uma situação de 'subordinação'. Além disso, a questão salarial é, segundo os relatos, outro assunto de polêmica entre ASBs e TSBs. Nos casos em que estes acabam desempenhando as mesmas funções daqueles, por subaproveitamento, cria-se um malestar, à medida que passam a receber mais, porém, desempenhando as mesmas atividades.

Ademais, alguns depoimentos remetem ao imaginário do CD, o qual vê o consultório dentário como seu lócus de atuação, onde predomina seu saber e seu poder. A centralidade no dente (Esposti, 2007; Emmerich, 200o) e o seguimento do modelo flexneriano (Queluz, 2009) determinaram a transformação do consultório privado como espaço único de produção de saúde bucal, onde é o CD quem decide como será seu trabalho (Emmerich, 200o; Pereira e col., 2003) e no fetiche que é a profissão. Nesse modelo, o "mocho4" pertence ao CD e a ninguém mais. Assim, inserir-se na área odontológica, em uma posição intermediária e numa profissão que só recentemente vem ampliando sua atuação, parece não ser fácil. 0 desconhecimento dos diversos profissionais sobre o trabalho dos TSBs prejudica as relações que se estabelecem na prática odontológica e, desse modo, podem resultar em uma atuação limitada desses profissionais.

\section{Considerações Finais}

O trabalho dos TSBs tem sido bastante estimulado no serviço público, principalmente após a inserção da saúde bucal na ESF. Num contexto de reorientação das práticas, é importante salientar que as contribuições dadas por essa categoria vão além da redução de custos. Assim, o processo de trabalho tem sido um foco de atenção especial do Ministério da Saúde por tratar-se de um cenário de difícil modificação.

Faz-se necessário o envolvimento de diversos atores nos encontros e desencontros, nos quais a subjetividade exerce grande papel. Outro fator que dificulta a modificação do processo de trabalho em saúde bucal é o fato de que, historicamente, seu modelo de atuação baseia-se em um ideário de especialização, de privilégio do biológico e do mercantil. Assim, tomando por base a necessidade de a Odontologia adequar-se a essa nova realidade dos serviços de saúde, torna-se imprescindível que ocorram modificações no processo de formação de seus profissionais, com a incorporação de novas práticas e de um discurso que se aproxime mais dos fundamentos propostos pela promoção de saúde bucal. Seria importante uma integração da graduação com a formação de recursos humanos auxiliares, enfim, que fosse multiprofissional e interdisciplinar.

Caso os TSBs sejam formados adequadamente e recebam condições de trabalho apropriadas, tanto física quanto em relação ao apoio institucional e dos demais membros da equipe de saúde, incluindo-se, especificamente, aqueles da área odontológica, eles terão condições de participar ativamente do processo de mudança dos serviços públicos de saúde bucal. Pelos resultados deste estudo, os CDs reconhecem a necessidade do trabalho em equipe, percebendo a participação dos TSBs como ponto favorável à reorientação das práticas e ao estabelecimento de um processo de trabalho que privilegie o atendimento das necessidades da comunidade. Como supervisores do trabalho dos TSBs e para poder explorar ao máximo as capacidades laborais desse profissional, os CDs precisam conhecer bem as atribuições desse profissional.

Embora os sujeitos entrevistados entendam como fundamental uma relação de parceria e de cooperação com os TSBs, existem muitas ideias negativas a respeito da atuação desses no serviço. Apesar dos avanços no campo legal, os CDs demonstram o receio de que os TSBs se tornem "dentistas práticos"; de perder lugar no mercado de trabalho para os TSBs

40 "mocho" é a cadeira em que o CD se senta para realizar o atendimento clínico ao paciente no consultório odontológico. 
e em relação à responsabilização legal sobre suas atividades, previsto na regulamentação do exercício da profissão. Outro aspecto levantado diz respeito à disputa de espaço e poder que se estabelece entre essas duas categorias profissionais, uma vez que se inserem em um mesmo campo de atuação. Além disso, a desinformação sobre a profissão de TSB por parte da equipe de saúde foi considerada um fator complicador para a construção de relações mais proveitosas e harmoniosas no processo de trabalho, de forma a produzir resultados mais efetivos no campo da saúde bucal.

\section{Agradecimentos}

À United Nations Educational, Scientific and Cultural Organization (UNESCO) e ao Ministério da Saúde do Brasil, pelo financiamento da pesquisa. À Secretaria Estadual de Saúde do Espírito Santo, por meio do Núcleo de Educação e Formação em Saúde (NUEFS), pela elaboração do projeto inicial de pesquisa, parceria técnica e administrativa. Ao Núcleo de Referência em Saúde, pela gestão administrativa e financeira que possibilitou o desenvolvimento da pesquisa.

\section{Referências}

ALCÂNTARA, C. M.; TAKAHASHI, A. R. W. Planejamento estratégico de cursos de ACD/THD - a experiência da Escola Técnica da Universidade Federal do Paraná. Revista da Abeno, Brasília, v. 6, n. 1, p. 28-34, 2006.

ARAÚJO, D. R. D. Como transcrever sua entrevista: técnica de editoração da transcrição de entrevista em pesquisa de abordagem compreensivista. PSICO, Porto Alegre, v. 32, n. 1, p. 147-157, jan./jun. 2001.

ARAÚJO, M. B. S.; ROCHA, P. M. Trabalho em equipe: um desafio para a consolidação da Estratégia de Saúde da Família. Ciência \& Saúde Coletiva, Rio de Janeiro, v. 12, n. 2, p. 455-464, 2007.

BARDIN, L. Análise de conteúdo. 2. ed. Lisboa: Edições 70, 2009.
BRASIL. Ministério da Saúde. Pesquisa Nacional de Saúde Bucal - BS Brasil 2010. Brasília, dez. 2010. Disponível em: <http://189.28.128.10o/dab/ docs/geral/apresentacao_SB-2010.pdf>. Acesso em: 07 jan. 2011.

BRASIL. Ministério da Saúde. Departamento de Informática do SUS. Brasília, [s.d.]. Disponível em: <http://w3.datasus.gov.br/datasus/datasus.php>. Acesso em: 20 ago. 2008.

BRASIL. Ministério da Saúde. Consolidado de equipes de saúde bucal e equipes de saúde da família. Brasília, jun. 2008a. Disponível em: <http://dab.saude.gov.br/abnumeros.php>. Acesso em: 16 out. 2011.

BRASIL. Lei n ${ }^{0} 11.889$ /o8, de 24 de dezembro de 2008 b. Regulamenta o exercício das profissões de técnico em saúde bucal - TSB e de auxiliar em saúde bucal - ASB. Disponível em: <http://www. jusbrasil.com.br/legislacao/92607/lei-11889-o8>. Acesso em: o6 jun. 2009.

BRASIL. Ministério da Saúde. Portaria nº. 648, de 28 de março de 2006. Disponível em: <http://dtr2004.saude.gov.br/dab/legislacao/ portaria_648_28_03_2006.pdf >. Acessado em: 25 maio 2006.

BRASIL. ACD e THD: regulamentar ou não? RETSUS, Rio de Janeiro, jul./ago. 2005. Disponível em: < http://bvsms.saude.gov.br/bvs/periodicos/ retsus_revista_10.pdf $>$. Acesso em: 24 nov. 2008.

BRASIL. Ministério da Saúde. Perfil de competências do técnico em higiene dental e do auxiliar de consultório dentário. Brasília, 2004a.

BRASIL. Ministério da Saúde. Projeto SB Brasil 2003: condições de saúde bucal da população brasileira 2002-2003: resultados. Brasília, 2004b. Disponível em: <http://bvsms.saude.gov.br/bvs/ publicacoes/projeto_sb2004.pdf >. Acesso em: 28 jan. 2006.

BRASIL. Ministério da Saúde. Diretrizes da Política Nacional de Saúde Bucal. Brasília, 2004c.

BRASIL. Ministério da Saúde. Programa Saúde da Família: equipes de saúde bucal. Brasília, 2002. Disponível em: <http://www.psfbrasil.com.br/ biblio/informes/it34.pdf $>$. Acesso em: 5 jul. 2005. 
BRASIL. Ministério da Saúde. Portaria nº. 1444, de 28 de dezembro de 2000. <http://www. mp.sc.gov.br/portal/site/portal/portal_lista. asp? campo=2527>. Acesso em: 22 maio 2006.

BRASIL. Ministério da Saúde. Guia curricular para a formação do técnico em higiene dental para atuar na rede básica do SUS. Área curricular I: prevenindo e controlando o processo de saúdedoença bucal. Brasília, 1994.

CAVACA, A. G. et al. Fatores associados ao interesse do cirurgião-dentista na docência para a formação do técnico em saúde bucal (TSB). Espaço para a saúde, Londrina, v. 11, n. 3, dez. 2010.

CONSELHO FEDERAL DE ODONTOLOGIA (CFO). Consolidação das normas para procedimentos nos Conselhos Regionais de Odontologia. Aprovada pela Resolução CFO-63/2005. Disponível em: <http://www.cfo.org.br/download/pdf/ consolidacao.pdf $>$. Acesso em: 26 fev. 2008.

CONSELHO FEDERAL DE ODONTOLOGIA (CFO). Dados estatísticos. Rio de Janeiro, [s.d]. Disponível em: <http://cfo.org.br/servicos-e-consultas/Dadosestatisticos/?elemento=profissionais\&categoria= TSB\&cro=Todos\&municipio=>. Acesso em: o6 out. 2011.

CHAVES, M. M. Odontologia social. 3. ed. São Paulo: Artes Médicas, 1986.

COSTA, H. Um Brasil sorridente. In: BRASIL. Ministério da Saúde. Perfil de competências profissionais do técnico em higiene dentale do auxiliar de consultório dentário. Brasília: Ministério da Saúde, 2004.

DEMO, P. Avaliação qualitativa. 3. ed. São Paulo: Cortez, 1991. Coleção Polêmicas do nosso tempo, v. 25 .

EMMERICH. A. A corporação odontológica e o seu imaginário. Vitória: Edufes, 2000.

EMMERICH, A.; CASTIEL, L. D. A ciência odontológica, Sísifo e o "efeito camaleão". Interface-Comunicação, Saúde, Educação, Botucatu, v. 13, n. 29, p. 339-351, abr./jun. 2009.
ESPÍRITO SANTO. Secretaria de Estado da Saúde. Perfil profissional dos cirurgiões-dentistas potenciais docentes do Curso Técnico em Higiene Dental da Região Metropolitana da Grande Vitória-ES. Vitória, 2008. 124p. (Relatório de Pesquisa).

ESPOSTI, C. D. D. A saúde bucal na saúde da família: ação comunicativa de Habermas guiando as relações. 2007. Dissertação (Mestrado em Saúde Coletiva) - Programa de Pós-Graduação em Saúde Coletiva da Universidade Federal do Espírito Santo, Vitória, 2007.

FARIA, H. X.; ARAÚJO, M. D. Uma Perspectiva de Análise sobre o Processo de Trabalho em Saúde: produção do cuidado e produção de sujeitos. Saúde e Sociedade, São Paulo, v.19, n.2, p.429-39, 2010.

FRAZÃO, P.; NARVAI, P. C. Lei ${ }^{0}{ }^{0} 11.889 / 2008$ : avanço ou retrocesso nas competências do técnico em saúde bucal? Trabalho, Educação e Saúde, Rio de Janeiro, v. 9, n.1, p. 109-23, mar./jun. 2011.

FRAZÃO, P. A participação do pessoal auxiliar odontológico na promoção de saúde bucal. Revista de Odontologia da Universidade de São Paulo, São Paulo, v. 12, n. 4, out./dez. 1998.

FRAZÃO, P.; CASTELLANOS, R. A. La participacion del personal auxiliar de odontologia em los sistemas locales de salud. Revista Panamericana de Salud Publica, Washington, DC, v. 5, n. 2, p. 10615, 1999.

GASKELL, G. Entrevistas individuais e grupais. In: BAUER, M.B.; GASKELL, G. (Org.). Pesquisa qualitativa com texto, imagem e som: um manual prático. Petrópolis: Vozes, 2002. p. 64-89.

GOMES, R. S.; PINHEIRO, R.; GUIZARDI, F. L. A orquestração do trabalho em saúde: um debate sobre a fragmentação das equipes. In: PINHEIRO, R.; MATTOS, R. A. de. Construção social da demanda: direito à saúde, trabalho em equipe, participação e espaços públicos. Rio de Janeiro: CEPESC/UERJ: ABRASCO, 2005. p. 105-16. 
GOMES, R. et al. Organização, processamento, análise e interpretação de dados: o desafio da triangulação. In: MINAYO, M. C. S.; ASSIS, S. G. de; SOUZA, E. R. de (Org.). Avaliação por triangulação de métodos: abordagem de programas sociais. Rio de Janeiro: Fiocruz, 2005. p. 185-222.

\section{INSTITUTO BRASILEIRO DE GEOGRAFIA E} ESTATÍSTICA. Departamento de emprego e rendimento. Acesso e utilização de serviços de saúde: 1998. Rio de janeiro: IBGE, 2000. Disponível em: <http://www.ibge.gov.br/home/ estatistica-/populacao/trabalhoerendimento/ pnad98/saude/saude.pdf>. Acesso: em 17 jun. 2006.

KOVALESKI, D. F.; BOING, A. F.; FREITAS, S. F. T. Recursos humanos auxiliares em saúde bucal: retomando a temática. Revista de Odontologia da Unesp, Araraquara, v. 34, n. 4, p. 161-65, 2005.

LIÑAN, M. B. G; BRUNO, L. E. N. B. Trabalho e formação profissional do atendente de consultório dentário e do técnico em higiene dental. Trabalho, educação e saúde, Rio de Janeiro, v. 5, n. 2, p. 297316, jul. 2007.

LOBO NETO, F. S. Ser professor: uma necessidade de formação. In: BRASIL. Ministério da Saúde. Projeto de profissionalização dos trabalhadores da área de enfermagem. Brasília: MS, 2002. v. 2, n. 4 , p. 5 .

MINAYO, M. C. S. O desafio do conhecimento: pesquisa qualitativa em saúde. 7. ed. São Paulo: Hucitec; Rio de Janeiro: ABRASCO, 2000.

NARVAI, P. C. Recursos humanos para promoção da saúde bucal: um olhar no início do século XXI. In: KRIGER, L. (Coord.). ABOPREV: promoção de saúde bucal. 3. ed. São Paulo: Artes Médicas, 2003. p. 475-94.

NARVAI, P. C. et al. Contra o técnico em higiene dental. Saúde em Debate, Londrina, n. 28, p. 59-65, 1989 .

NARVAI, P.C. et al. Cárie dentária no Brasil: declínio, iniquidade e exclusão social. Revista Panamericana de Salud Pública, Washington DC, v. 19, n. 6, p. 385-93, 2006.
NOGUEIRA, R. P. Trabalho e qualidade em serviços de saúde. In: SANTANA, J. P. Capacitação em desenvolvimento de recursos humanos de saúde: CADRHU. Natal: UFRN, 1999. p. 109-13.

PEDUZZI, M. Equipe multiprofissional de saúde: conceito e tipologia. Revista de Saúde Pública, São Paulo, v. 35, n. 1, p. 103-9, 2001.

PEDUZZI, M. Trabalho em equipe de saúde no horizonte normativo da integralidade, do cuidado e da democratização das relações de trabalho. In: PINHEIRO, R.; BARROS, M. E. B. de; MATTOS, R.

A. Trabalho em equipe sob o eixo da integralidade: valores, saberes e práticas. Rio de Janeiro: IMS/ UERJ: CEPESC: ABRASC0, 2007. p. 161-77.

PEREIRA, A. C.; MOREIRA. B. W. A utilização do auxiliar odontológico para o aumento da produtividade nos serviços públicos. Revista da Associação Paulista de Cirurgiões Dentistas, São Paulo, v. 46, n. 5, set./out. 1992.

PEREIRA, D. Q.; PEREIRA, J. C. M.; ASSIS, M. M. A. A prática odontológica em unidades básicas de saúde em Feira de Santana (BA) no processo de municipalização da saúde: individual, curativa, autônoma e tecnicista. Ciência \& Saúde Coletiva, Rio de Janeiro, v. 8, n. 2, p. 599-609, 2003.

PEZZATO, L. M.; COCCO, M. I. M. O técnico em higiene dental e o atendente de consultório dentário no mundo do trabalho. Saúde em Debate, Rio de Janeiro, v. 28, n. 68, p. 212-219, set./dez. 2004 .

PUCCA JR., G. A. A política nacional de saúde bucal como demanda social. Ciência \& Saúde Coletiva, Rio de Janeiro, v. 11, n. 1, p. 243-6, 2006.

QUELUZ, D. P. Recursos Humanos em Odontológica. In: PEREIRA, A.C. Tratado de saúde coletiva em odontologia. São Paulo: Napoleão, 2009. p. 162-98.

QUELUZ, D. P. Perfil dos profissionais auxiliares da odontologia e suas implicações no mercado de trabalho. Revista Odonto Ciência, Porto Alegre, v. 20, n. 49, jul./set. 2005. 
QUELUZ, D. P. Recursos humanos na área odontológica. In: PEREIRA, A.C. Odontologia em saúde coletiva: planejando ações e promovendo saúde. Porto Alegre: Artmed, 2003. p. 140-59.

SBRAVATI, R. S.; MENEGHIM, M. C.; PEREIRA, A. C. T. H. D. No mercado de trabalho: uma realidade? Revista Robrac - Revista Odontológica do Brasil Central, Goiânia, v. 8, n. 25, p.37-9, 1999.

SERRA, M. C.; SASSO GARCIA, P. P. N. Delegação de funções: utilização de pessoal auxiliar na clínica odontológica. Revista ABO Nacional, Recife, v. 10, n. 2, p. 98-104, 2002.

SILVA, R. F. et al. Utilização de auxiliares odontológicos em Ortodontia: implicações éticas e legais. Revista Dental Press Ortodon Ortop Facial, Maringá, v. 11, n. 5, p. 121-128, set./out. 2006.
SOUZA, E. R. De, et al. Construção dos instrumentos qualitativos e quantitativos. In: MINAYO, M. C. de S.; ASSIS, S. G. de; SOUZA, E. R. de (Org.). Avaliação por triangulação de métodos: abordagem de programas sociais. Rio de Janeiro: Fiocruz, 2005. p. 133-56.

TEIXEIRA, C. F. O processo de trabalho da vigilância em saúde. In: TEIXEIRA, C. F. Programa de Formação de Agentes Locais de Vigilância em Saúde: PROFORMAR. Rio de Janeiro: Fiocruz: Escola Politécnica Joaquim Venâncio, 2003. (Unidade 1, módulo 2, p. 26-27). 